\title{
Role of the Matrix Metallo-Proteinases in the Cellular Re-Modeling in a Glaucoma Model System in Rat
}

\author{
Claudio De Seta, Nicola Calandrella, Valerio Berardi, Antonio Mazzarelli, \\ Gianfranco Scarsella and Gianfranco Risuleo* \\ Dipartimento di Biologia e Biotecnologie "Charles Darwin" \\ - Sapienza Università di Roma, \\ Italy
}

\section{Introduction}

Glaucoma is a degenerative and progressive pathology involving the optic nerve with consequent loss of the visual field: it is a particularly severe ocular affection constituting the second cause of blindness in the world. This disease may occur at any age even though it is more frequently found in senior people (Quigley, 1987; Morgan, 2000). Five different types of the disease have been described: two of them are defined as primary open angle or, alternatively, closed angle, which is possibly the most common one (Joseph \& Grienson, 1994). Retinal gangliar cells were reported to be the ones mainly damaged by the disease as shown in classical studies by Quigley (Quigley et al., 1998). The disease causes a reduction of the axons forming the optic nerve (Capaccioli et al., 1998). The etiology of glaucoma may be due to two different types of damage: either mechanical or ischemic. In any case, it is commonly accepted that an increased intraocular pressure represents a major risk factor in the development of the disease, and actually, it may be one of the principal causes (Quigley et al., 1994; De Gregorio et al., 1997; Sommers et al., 1991; Friedman et al., 2004). Under the clinical point of view, the increase of pressure is apparently attributable to the alteration of the ocular hydrodynamics, which determines a normal efflux of the aqueous humor from the anterior chamber. Different types of glaucoma exist in particular, in the case of the open angle glaucoma, the lack of efflux depends particularly on obstructions in the trabecular network, while the primary closed angle glaucoma involves a modification the irido-corneal angle. Other ocular pathologies exist where the vitreous efflux is altered but, in these cases, the pathology is defined as secondary glaucoma: also in this pathological condition, the open and the closed angle have been described. In any case, the elevated intraocular pressure seems to be the most relevant pathogenic phenomenon determining the neuropathy although it may be not the only one (Quigley et al., 1994; De Gregorio et al., 1997; Sommers et al., 1991). With respect to this, the synergic action of other factors seems to be proved by the existence of glaucomatous pathologies occurring in conditions of normal ocular pressure: however, a reduced retinal and optic nerve perfusion could play a role due to a deficient blood delivery to these ocular structures. The immunological aspect of the disease should be also considered: for instance in glaucoma patients several auto-immuno 
markers were detected (Wax et al., 2000). However, the role of the humoral immunity is far from clear, even though the immuno-system could play a role in the development and/or progression of the pathological condition (Pescosolido et al., 2008). In the light of the aspects so far discussed, it is plausible assuming that the immune system plays an active role in triggering the neuro-degenerative process, which could be very likely, started by the glial cells. These, by producing cytokines and presentation of antibodies, lead to the elicitation of cytotoxic autoantibodies as previously discussed (Calandrella et al., 2010).

In our laboratory, we developed an effective experimental rat model of acute ocular hypertension where the hyper-tone was induced by injection of methylcellulose in the anterior chamber. This inert non-immunogenic substance clogs the Schlemm's canals thus causing the accumulation of aqueous humor with consequent increase of intra-ocular pressure: therefore, the pathological conditions found in the human glaucoma are reproduced. The increased intra-ocular pressure (IOP) eventually determines a damage at the level of the retinal cells which can be controlled by L-carnitine, a well known peroxide scavenger (Calandrella et al., 2007; Calandrella et al. 2010). In this work, we focus on the morphological and functional alterations of the ocular nervous structures consequent to the hypertensive stress. In particular, we have examined the possibility that L-carnitine can antagonize the damage due to the production of free radicals that are formed in significant amounts during a situation of ischemia/re-perfusion. In other words, we probed the hypothesis that L-carnitine may play an anti-apoptotic role via the improvement of the mitochondrial performance and the stabilization of the membrane of this cell organelle (Ishii et al., 2000). To this end, we present data on the on the alterations of the expression of the Matrix-Metallo-Proteases (MMP) -2 and -3. These enzymes are involved, respectively, in the degradation of type IV collagen and of a wide range of proteins of the extracellular matrix such as fibronectin, proteoglycans and lamin. We also present results on the level of expression of the inducible Nitric Oxide Synthase (iNOS), one of the principal enzymes responsible for the production of free radicals in the retina and optic nerve subjected to the hypertensive shock. To ascertain the actual extent of oxidative damage we also measured the level of membrane lipo-peroxidation and, finally, we assessed the mode of cell death by the evaluation annexin $\mathrm{V}$, an early marker of apoptosis and caspase-3, a protease executing the apoptotic death program.

\section{Materials and methods}

\subsection{Animals and induction of the hyper-tone}

We used 5 different male Wistar rats (weight 300-500 grams) in each experimental session. In every animal, one eye was subjected to the treatment while the contra-lateral one represented the untreated sham-operated control. The experimental model of hyper-tone induction was derived from the one published by Zhu and Cai in rabbits but adapted to rats (Zhu \& Cai 1992). Where applicable, L-carnitine (obtained from Sigma-Tau, Italy) was used at $0,6 \mathrm{mM}$ (concentration which refers to the solution applied to the animal's eye). Animals were sacrificed at the indicated time post-treatment by carotid haemorrhage and the eyes were enucleated for analysis. The cornea was eliminated at the level of the corneal limbus and emptied of the crystalline lens and aqueous humor.

For details about methyl-cellulose injection, time course and measurement of the ocular hyper-tone, local and general anesthesia as well as surgical manipulations see: (Calandrella et al., 2007; Calandrella et al., 2010). 


\subsection{Cell biology assays}

Immunolocalization was performed as previously reported (Calandrella et al., 2007). Immuno-histochemical assays were used to assess the level of Matrix-Metallo-Proteases $2 \mathrm{e}$ 3 (MMP-2 MMP-3), inducible Nitric Oxide Synthase (iNOS), annexinV and caspase-3; for details see (Calandrella et al., 2007; Calandrella et al., 2010). Immunohistochemistry samples were fixed and stored at $-20^{\circ}$ for subsequent microscopy observation.

\subsection{Biomolecular assays}

Western blottings and lipoperoxidation assays were performed on control and carnitine treated retinal cell extracts. Total protein extracts were prepared by standard procedures and analyzed by PAGE using the following antibodies: caspase 3 (active form), iNOS (Santa Cruz) and ubiquitin (Sigma-Aldrich). Actin was used as standard reference (Sigma-Aldrich). To determine the oxidative stress at membrane level we used a quantitative assay based on the intracellular production of malonyl-dialdehyde (MDA, commercial kit LPO-586 Oxis Health Research Products Portland, Or. USA). The reaction of a single MDA molecule with NMP molecules generates a stable chromophore whose absorbance is measured at a $586 \mathrm{~nm}$. Absorbance values can be directly converted in molar concentration of MDA.

\subsection{Statistical analysis}

All the experiments were repeated at least three times. Statistical analysis of the results was made by the Student's t-test or by a two-way analysis of variance (ANOVA) followed by the Student's t-test. P-values < 0.05 were considered significant. Ocular inflammation was evaluated by the Drize test (Drize, 1944). The experimentation was performed according the guidelines ARVO (Association for Research in Vision and Ophthalmology). In any case, this research was conducted according to the International Guiding Principles for Biomedical Research Involving Animals recommended by WHO on animal research; all Italian and European regulations on animal research were also respected.

\section{Results and discussion}

\subsection{Alterations of the extracellular matrix: Role of Matrix-Metallo-Proteases (MMP -2 and 3)}

As previously shown in our laboratory, in the glaucomatous pathology an extensive matrix remodeling is observed at the level of the head of the optic nerve; this is associated to the increase of intra-ocular pressure (Calandrella et al., 2007; Calandrella et al., 2010). Remodeling of the extra-cellular matrix, induced by neural damage, is mediated by the MMPs which are normally regulated by specific inhibitors known as TIMPs. These enzymes are expressed in a constitutive manner in the retina, in particular in the retinal gangliar cells (RGC), while in the optic nerve MMPs are expressed by astrocytes. This suggests their involvement in the maintenance of the synaptic integrity and plasticity as well as the periaxonal space. In a first series of experiments, we assessed the matrix re-modeling by immunolocalization of MMP-2 and MMP-3. Data presented in Figure 1 show that methylcellulose (MTC) induces a drastic increase of the MMP-2 expression in the retina (Right upper panel). The fluorescent reaction is strongly reduced by contemporary injection of MTC and L-Carnitine (Center lower panel) thus suggesting the protective role of this drug. 

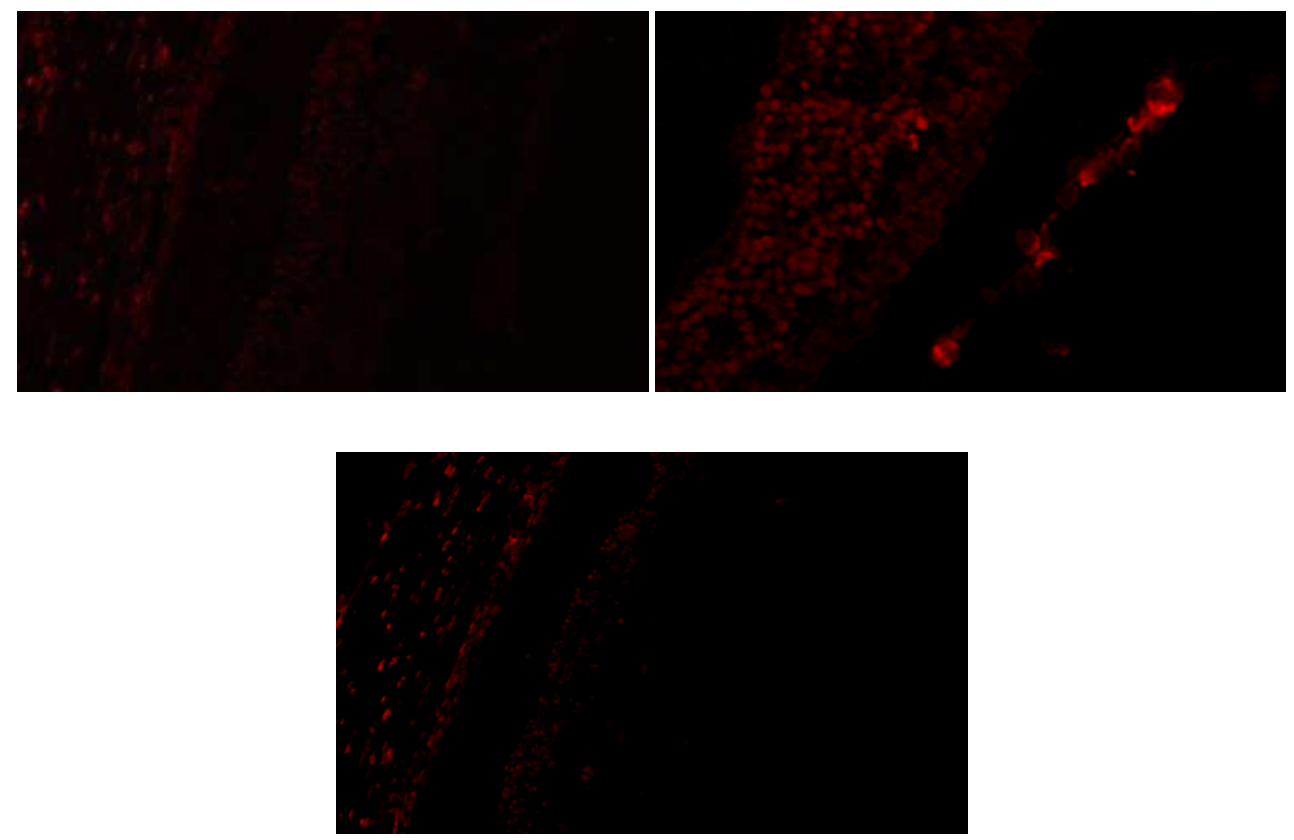

Fig. 1. Increase of the MMP-2 expression in the retina as shown by fluorescent reaction (Right upper panel), which is strongly reduced by contemporary injection of MTC and LCarnitine (Center lower panel). The left upper panel refers to untreated control eyes.

We obtained similar results also after immunolocalization of the MMP-3 (Figure 2, Left upper panel and lower center panel, respectively); actually, the expression of this enzyme is significantly reduced in the presence of L-carnitine.

The molecular target of the two MMPs is different since the first one cleaves type IV collagen while the second one degrades a broader range of proteins such as fibronectin, laminine and proteoglycans (Woessner, 1991). We monitored analogous results in immunolocalization analysis of the optic nerve, also in the over-expression of MMPs whose reduction is mediated by L-carnitine. Interestingly, the columnar organization of the astrocytes is lost after treatment with MTC but is moderately restored by L-carnitine. With respect to this, the presence of an increased expression of the MMPs was previously observed in the vitreous and cultured cells of the trabecular network. Actually, data from other laboratories suggest that, due the broad range of substrates processed by MMP-3, the over-expression of this enzyme is per se sufficient to cause re-modeling of the trabecular tissue in the open angle glaucoma after ex vivo reperfusion of the eye (Pang et al., 2003). Therefore, the original data is that in our case matrix remodeling is also observed in the posterior area of the eye.

From these results, we can draw a first conclusion: L-carnitine can counteract the effects of the hypertone due to the injection MTC. In other words, the extracellular matrix remodelling 
can be controlled by the cytoprotective action of L- carnitine, which improves the membrane stability and consequently, leads to better interactions between the cell and the extracellular matrix.
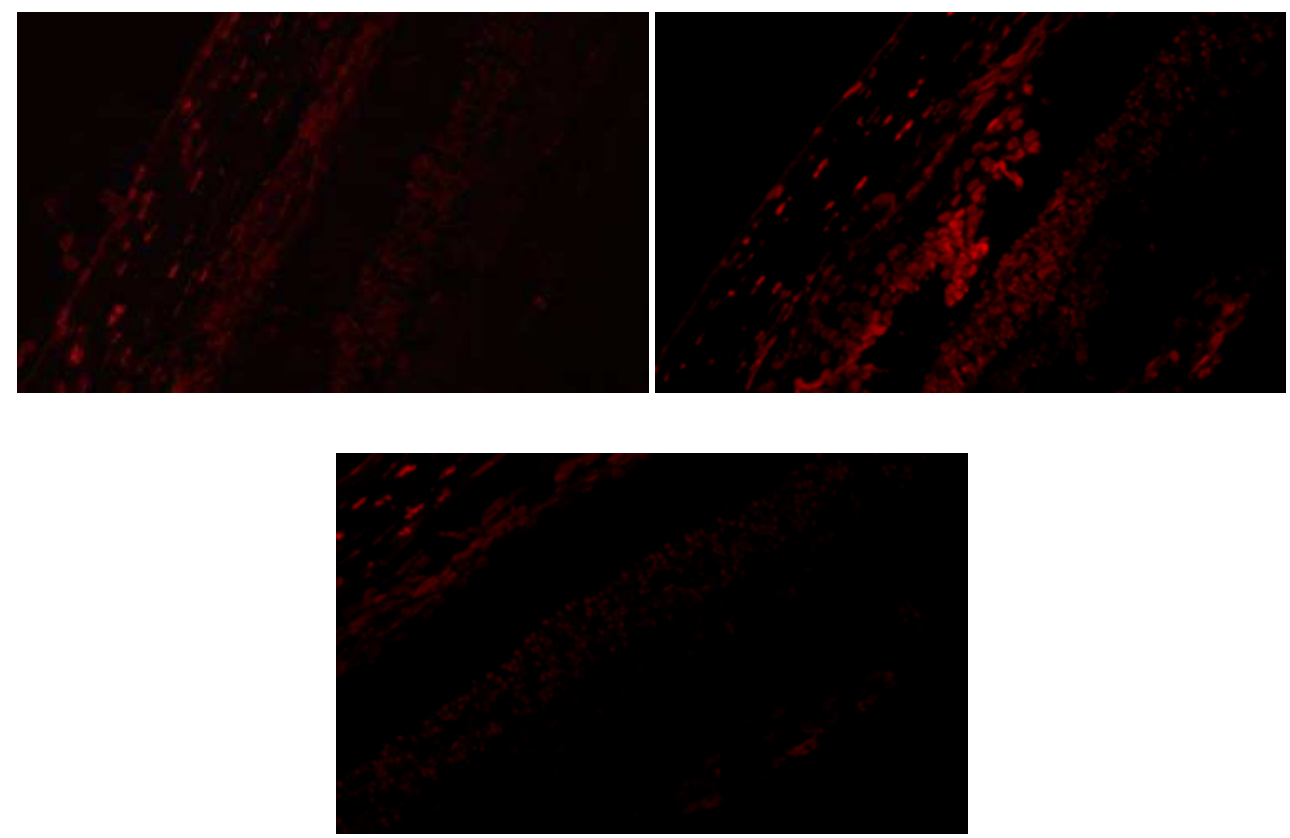

Fig. 2. Immunolocalization of the MMP-3 after treatment with MTC (Right upper panel). The expression of this enzyme is significantly reduced in the presence of L-carnitine (Lower center panel). Left upper panel is as in Figure 1.

\subsection{Oxidative stress as a consequence of the acute ocular hypertension}

The cellular damage due to the hypoxi/re-oxigenative stress may trigger the production of free radicals with consequent destabilization of the cell membranes (Calandrella et al., 2010). As a matter of fact literature data show that the ischemic insult at retinal level activates iNOS which leads to the production of nitrogen oxide (Goldstein et al., 1995; Geyer et al., 1995): this compound is cytotoxic at high concentration and causes lipid peroxidation (Crow et al., 1996; Ullrich et al., 2000). It was also shown that iNOS expression is responsible for the retinal cell death both in vitro and in vivo (Sennlaub et al., 2002). In the light of these data, we evaluated the level of this enzyme as a consequence of the hypertensive shock caused by MTC and if its expression could be modulated by parallel administration L-carnitine. The experimental approach is essentially analogous to the one adopted for the determination of MMP-2 and -3 (the results of immunolocalization assays are not shown). We also carried a Western blot evaluation of the iNOS level. It worth noting that, unlike the previous immunolocalization assays, the Western blot allows a simpler and more immediate 
quantification of the iNOS concentration. Results show (Figure 3) that in protein extracts of retina, a protein band of $130 \mathrm{kDa}$ is observed representing the iNOS already hours 6 after the treatment with MTC (immunoblot at 24 hours is omitted). The actin band (50 kDa) was used as reference standard in this and the following Western blotting assays.

This indicates that the up-regulation of iNOS and the consequent production of nitric oxide, are early reactions to the hypertensive shock. As expected in the animals treated also with Lcarnitine the enzyme immuno-band is significantly reduced. This validates the idea that the drug exerts a strong cytoprotective action during the re-oxigenation and reperfusion process (Mutomba et al., 2000; Di Marzio et al., 1997; Pillich et al., 2005). Similar results were obtained 24 hour after the treatment. The data are quantified in Figure 4.

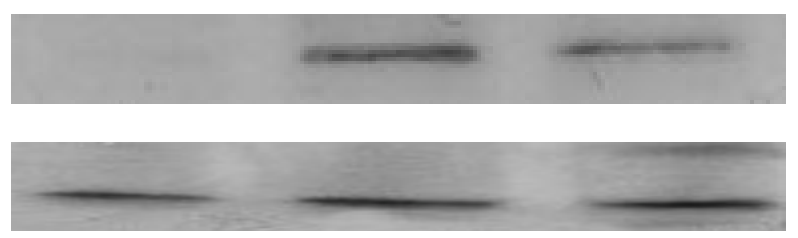

Fig. 3. Treatment of the rat eye with MTC for 6 hours induces a strong induction of the iNOS (Upper panel, center lane) as compared to the control eye where the iNOS band is decreased (Upper panel, left lane). This over-expression is reduced significantly by contemporary treatment with L-carnitine (Upper panel, right lane). The lower panel refers to the actin immunoreaction used as standard (See Figure 4).

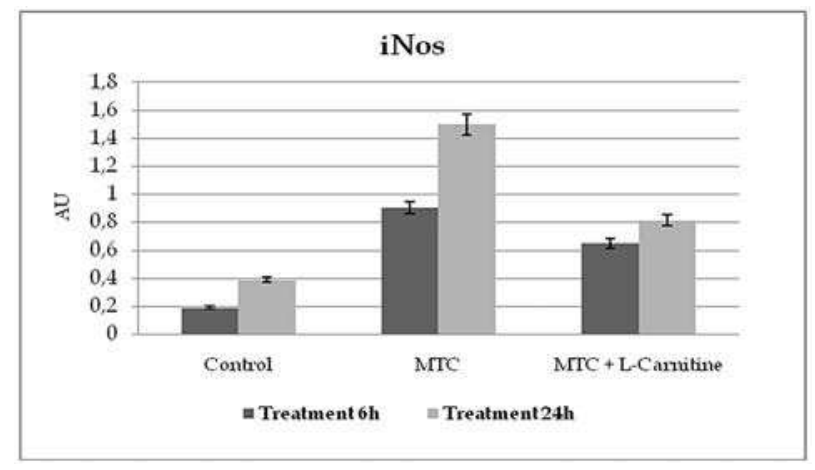

Fig. 4. Quantification of the Western blotting data presented in figure 3. Quantification refers both to 6 and to 24 hours post-treatment.

In the light of these results, we also assessed the level of lipid peroxidation, which is commonly accepted as an indicator of oxidative stress in cultured cells and in tissues (Petit et al., 1995; Chancerelle and Kergonou, 1995). This assay is based on the quantitative evaluation of the intracellular concentration of malonyl-dihaldeyde (MDA). This compound 
is not normally present in the cells but is formed after an oxidative stress and is also considered a marker of membrane damage; as a matter of fact MDA is one of the main products of the decomposition of poly-unsaturated fatty acids.

The lipoperoxidation assay, performed three hours after the treatment with MTC (Fig 5, central bar), indicates a dramatic increase of the MDA concentration as compared to control retinas (left bar). However, the production of this compound is significantly reduced if MTC is administered to the rat in the presence of L-carnitine. This validates the idea that Lcarnitine stabilizes the lipid membrane and improves the mitochondrial performance. The final result is the reduction of the lipid peroxidation derived by the hypertensive shock.

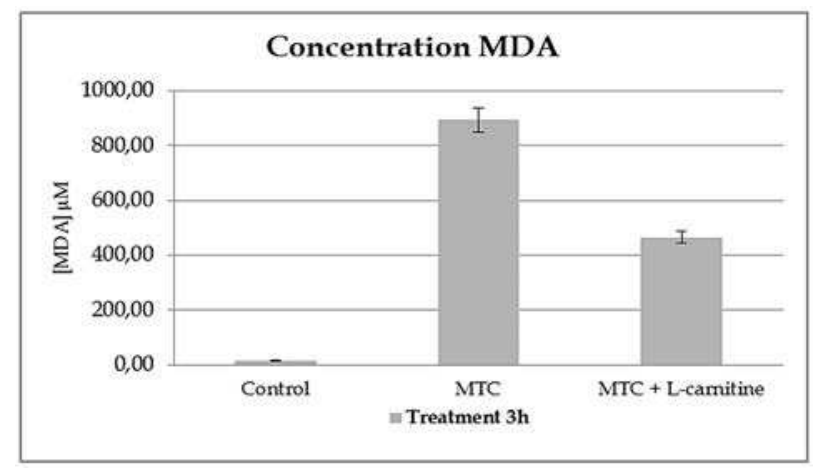

Fig. 5. Lipoperoxidative damage induced by MTC (Central bar) treatment is drastically reduced by L-carnitine (Right bar).

\subsection{Mechanisms of programmed cell death: expression of annexin V and caspase-3}

In this final series of experiments, we monitored the level of two different apoptotic markers: annexin $\mathrm{V}$ and caspase -3 . The rationale of these experiments was that in the early stages of apoptosis the phospho-lipid symmetry of the membrane is altered; annexin $\mathrm{V}$ is included in a family of proteins known to bind phospholipids in the presence of $\mathrm{Ca}^{2+}$ ions. In particular, it interacts with phosphatidyl-serine, which is translocated to the outer face of the membrane thus becoming a recognition signal for phagocytes (Lazebnick et al., 1994). We evaluated the expression of this early marker of apoptosis by immuno-blotting, both after treatment of the eye with MTC only, or MTC in the presence of L-carnitine.

The level of annexin V was normalized to the one of actin, which is expressed in a constitutive fashion. Results of Figure 6 clearly show that contemporary treatment with MTC and L-carnitine reduces significantly the level of annexin V already 6 hours posttreatment (the immunoblot picture is reported only for the treatment time at 6 while the quantitative analysis refers both to 6 and 24 hour treatment). The low level of Annexin V monitored after 24 hours of treatment (immunoblot not shown, quantification in Figure 7) is possibly due to the advanced phase of apoptosis since this marker is expressed mainly in the early phases of the process (Lazebnick et al., 1994).

The low level of annexin $\mathrm{V}$ observed also in untreated eyes may be ascribed to the "physiological" expression on this protein as observed previously or, alternatively, to a 
generic damage inflicted to the eye while carrying out the experimental protocol (Calandrella et al., 2010).
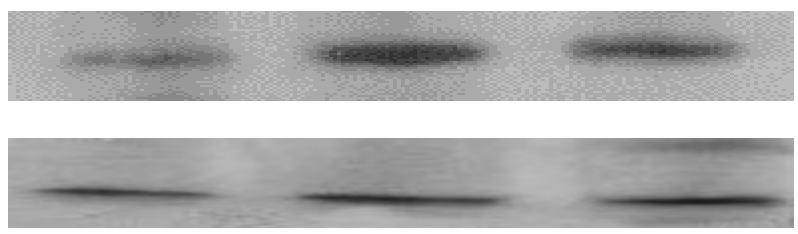

Fig. 6. Expression annexin V both after treatment of the eye with MTC only (Center lane), or MTC in the presence of L-carnitine (Right lane). Also in this case as in the previous figure, actin (Lower panel) was used as reference standard for the quantification reported below.

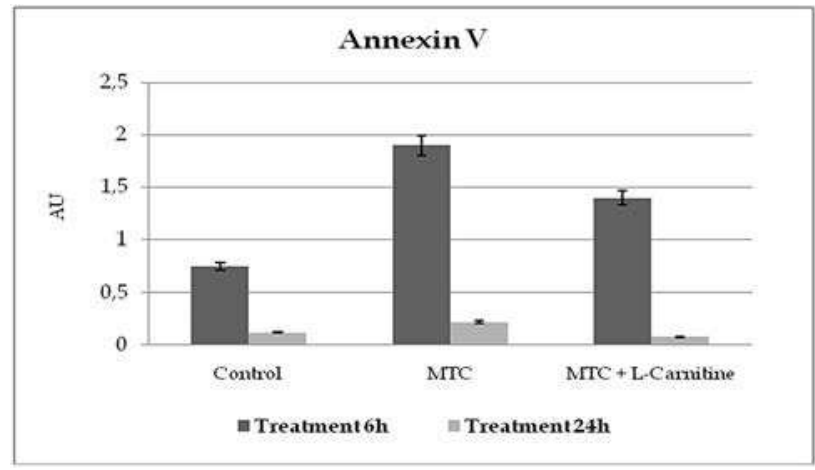

Fig. 7. Levels of annexin V after treatment with MTC or MTC plus carnitine. Also in this case as in the previous figure actin was used as reference standard.

Caspase-3 is the enzyme responsible for the execution of the final phases of apoptosis. Therefore, the Western-blot analysis was performed both after 6 and 24 hours of treatment with MTC (or in association with L-carnitine). This experiment allows also evaluating whether L-carnitine is able to reduce the apoptotic death by modulating in a negative fashion the expression of caspase-3 (Mutomba et al., 2000, Calandrella et al. 2007). Data reported in Figure 8 (Upper panel, right lane) clearly show that the expression of caspase-3 in retinal cell extracts is strongly reduced at 24 hours after the treatment with MTC in the presence of L-carnitine.

However, 6 hours after the treatment the level of caspase- 3 is practically identical to control samples. This suggests that L-carnitine acts also in advanced stages of the apoptotic process but prior to irreversibility. 


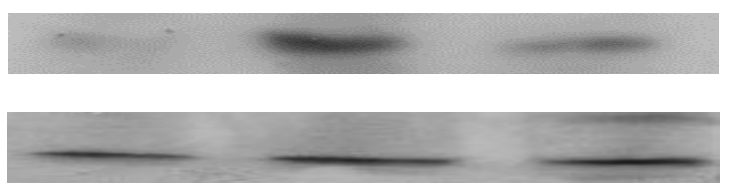

Fig. 8. The expression of caspase-3 (Center lane) in retinal cell extracts is strongly reduced at 24 hours after the treatment with MTC in the presence of L-carnitine (Right lane). Actin (Lower panel) was used as reference standard for the quantification reported below.

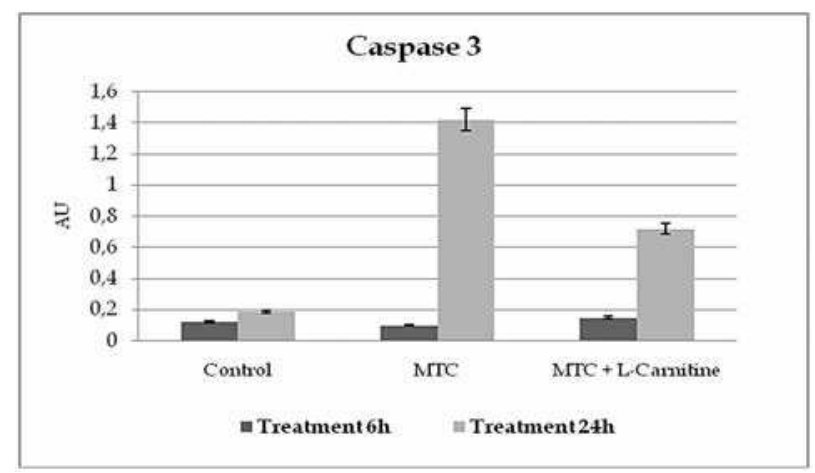

Fig. 8. Quantification of the data in the previous figure (normalized to actin).

\section{Conclusions}

In this study, we induced the hypertensive stress inoculating methyl-cellulose in the anterior chamber of the eye in a rat model system. This mimics the pathological situation occurring in the human glaucoma (Calandrella et al., 2010). The results of our investigations demonstrate that L-carnitine, a well known scavenger of reactive peroxides (Pollit, 1995; Stephens et al., 2007), can exert a cytoprotective action which involves the reduction of the expression of metalloprotease -2 and -3 . We also monitored a down-regulation of typical apoptotic markers such as annexin V and caspase 3. The decrease of the level of iNOS, induced by L-carnitine and the consequent reduction of intracellular MDA finally suggests that this compound may also limit the damage due to the oxidative stress. In conclusion, these results may be very useful in the elucidation of the pathological and molecular phenomena occurring during the progression of the human glaucoma. Also, these data may open the way to a possible solution of this pathological condition.

\section{References}

Calandrella, N.; De Seta, C.; Scarsella, G. \& Risuleo, G. (2010). Carnitine reduces the lipoperoxidative damage of the membrane and apoptosis after induction of cell stress in experimental glaucoma. Cell Death and Disease, Vol. 1, No. 8, 
(Aug 5), pp. e62, doi:10.1038/cddis.2010.40. ISSN (online): 2041-4889. On line publication

Calandrella, N.; Scarsella, G.; Pescosolido, N. \& Risuleo, G. (2007). Degenerative and apoptotic events at retinal and optic nerve level after experimental induction of ocular hypertension. Molec. Cell. Biochem, Vol. 301, No. 1-2, (July 2007), pp. 155-163

Capaccioli, S.; Nucci, C.; Quattrone, A. \& Carella, E. (1998). Apoptosi nel glaucoma. In: Apoptosi in oftalmologia, Ed I.N.C., pp. 44-57, Roma

Chancerelle, Y. \& Kergonou, J.F. (1995). Immunological relevance of malonic dialdehyde. Ann. Pharm. Fr., Vol. 53, No. 6, pp. 241-50

Crow, J.P. \& Beckman, J.S. (1996). The importance of superoxide in nitricoxide-dependent toxicity: evidence for peroxynitrite-mediated injury. Adv. Exp. Med. Biol., Vol. 387, pp. 147-61

De Gregorio, F.; Pecori Giraldi, J.; De Stefano, C. \& Virno, M. (1997). Correlation between ocular hypertension induced by ibopamine and perimetric defect in primary open angle glaucoma. Eur. J. Ophthalmol., Vol. 7, No. 2, pp. 152-55

Di Marzio, L.; Alesse, E.; Roncatoli, P.; Muzi, P.; Moretti, S.; Marcellini, S.; Amicosante, G.; De Simone, C. \& Cifone, M.G. (1997). Influence of L-carnitine on CD95 crosslinking-induced apoptosis and ceramide generation in human cell lines: correlation with its effects on purified acidic and neutral sphingomyelinase in vitro. Proc. Assoc. Am. Physicians, Vol. 109, No. 2, (Mar 1997), pp. 154-63

Drize, J.H.; Woodard, G. \& Calvery, H.O. (1944). Methods for the study of irritation and toxicity of substances applied topically to the skin and mucous membranes. J. Pharm. Exp. Ther., Vol. 82, pp. 377-90

Friedman, D.S.; Wilson, M.R.; Liebmann, J.M.; Fechtner, R.D. \& Weinreb, R.N. (2004). An evidence-based assessment of risk factors for the progression of ocular hypertension and glaucoma. Am. J. Ophthalmol., Rev Vol. 138, No. 3, (Sep 2004), pp. S19-31

Geyer, O.; Almong, J.; Lupu-Meiri, M.; Lazar, M. \& Oron, Y. (1995). Nitric oxide sinthase inhibitors protect rat retina against ischemic injury. FEBS Letters, Vol. 374, No. 3, (Nov 1995), pp. 399-402

Goldstein, I.M.; Ostwald, P. \& Roth, S. (1995). Nitric oxide: a review of its role in retinal function and disease. Vision. Res., Vol. 36, No. 18, (Sep 1996), pp. 2979-94

Ishii, T.; Shimpo, Y.; Matsuoka, Y. \& Kinoshita, K. (2000). Anti-apoptotic effect of Acetyl-Lcarnitine and L-carnitine in primary cultured neurons. Jpn. J. Pharmacol., Vol. 83, No. 2, (Jun 200), pp. 119-24

Joseph, J. \& Grienson, I. (1994). Anterior segment changes in glaucoma. In: Pathology of ocular disease: a dinamic approach. Ed. Garner A. \& Klintworth G.H., Marcel Dekker Inc.

Lazebnik, Y.A.; Kaufmann, S.H.; Desnoyers, S.; Poirier, G.G. \& Earnshaw, W.C. (1994). Cleavage of poly(ADP-ribose) polymerase by a proteinase with properties like ICE. Nature, Vol. 371, No. 6495, (Sep 1994), pp. 346-7

Morgan, J.E. (2000). Optic nerve head structure in glaucoma: astrocytes as mediators of axonal damage. Eye, Vol. 14, No. Pt3B, (Jun 2000), pp. 437-44 
Mutomba, M.C.; Yuan, M.; Adachi, S.; Yokoyama, C.B.; Esser, V.; McGrarry, J.D.; Babior, B.M. \& Gottileb, R.A. (2000). Regulation of the activity of caspase by L-carnitine and palmitoylcarnitine. FEBS Lett., Vol. 478, No. 1-2, (Jul 2000), pp. 19-25

Pang, I.; Fleenor, D.L.; Hellberg, P.E.; Stropki, K.; McCartney, M.D. \& Clark, A.F. (2003). Aqueous Outflow-Enhancing Effect of tert-Butylhydroquinone: Involvement of AP-1 Activation and MMP-3 Expression. Invest. Ophthalmol. Vis. Sci., Vol. 44, No. 8, (Aug 2003), pp. 3502-3510

Pescosolido, N.; Imperatrice, B. \& Karavitis, P. (2008). Ocular disorders secondary to systemic disease and the potential role of carnitines. Drugs R. D., Vol. 9, No. 1, pp. 15-22, doi: 10.2165/0126839-200809001-00003

Petit, E.; Divoux, D.; Chancerelle, Y.; Kergonou, J.F. \& Nouvelot, A. (1995). Immunological approach to investigating membrane cell damages induced by lipoperoxidative stress. Application to far UV-irradiated erythrocytes. Biol. Trace. Elem. Res., Vol. 47, No. 1-3, (Jan-Mar 1995), pp. 17-27

Pillich, RT.; Scarsella, G. \& Risuleo, G. (2005). Reduction of apoptosis through the mitochondrial pathway by the administration of acetyl-L-carnitine to mouse fibroblasts in culture. Exp. Cell. Res., Vol. 306, No. 1, (May 15), pp. 1-8

Pollitt, R.J. (1995). Disorders of mitochondrial long-chain fatty acid oxidation. J. Inherit. Metab. Dis., Vol. 18, No. 4, pp. 473-90, Review

Quigley, H.A.; Dunkelberger, G.R. \& Green, W.R. (1989). Retinal ganglion cell atrophy correlated with automated perimetry in human eyes with glaucoma. Am. J. Ophthalmol., Vol. 107, No. 5, (May 1989), pp. 453-64

Quigley, H.A. (1987). Reappraisal of the mechanism of glaucomatous optic nerve damage. Eye Vol. 1, No. Pt2, pp. 318-22

Quigley, H.A.; Enger, C.; Katz, J.; Sommer, A.; Scott, R. \& Gilbert, D. (1994). Risk factors for the development of glaucomatous visual field loss in ocular hypertension. Arch. Ophthalmol., Vol. 112, No. 5, (May 1994), pp. 644-9

Sennlaub, F.; Courtois, Y. \& Goureau, O. (2002). Inducible nitric oxide synthase mediates retinal apoptosis in ischemic proliferative retinopathy. J. Neurosci., Vol. 22, No. 10, (May 2002), pp. 3987-93

Sommers, A.; Tielsh, J.M. \& Katz, J. (1991). Relationship between intraocular pressure and primary open angle glaucoma among white and black Americans. Arch. Ophthalmol., Vol. 109, No. 8, (Aug 1991), pp. 1090-5

Stephens, F.B.; Constantin-Teodosiu, D. \& Greenhaff, P.L. (2007). New insights concerning the role of carnitine in the regulation of fuel metabolism in skeletal muscle. J. Physiol., Vol. 581, No. Pt2, (Jun 2007), pp. 431-44

Ullrich, V. \& Bachschmid, M. (2000). Superoxide as a massanger of endothelial function. Biochem. Biophys. Res. Comm., Vol. 278, No. 1, (Nov 2000), pp. 1-8 Review

Wax, M.B.; Tezel, G.; Kobayashi, S. \& Hernandez, M.R. (2000) Responses of different cells lines from ocular tissues to elevated hydrostatic pressure. Br. J. Ophthalmol., Vol. 84, No. 4, (Apr 2000), pp. 423-8

Woessner, J.F. Jr. (1991). Matrix metalloproteinases and their inhibitors in connective tissue remodeling. FASEB J., Vol. 5, No. 8, (May 1991), pp. 2145-54 Review 
Zhu, M.D. \& Cai, F.Y. (1992). Development of experimental chronic intraocular hypertension in the rabbit. Austl. Nw. Z. J. Ophthalmol. Vol. 20, No. 3, (Aug 1992), pp. 225-34 


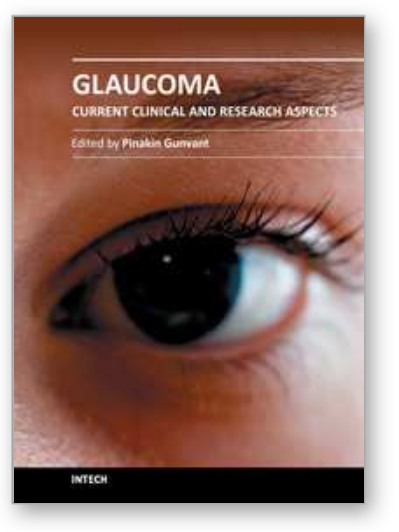

\author{
Glaucoma - Current Clinical and Research Aspects \\ Edited by Dr. Pinakin Gunvant
}

ISBN 978-953-307-263-0

Hard cover, 376 pages

Publisher InTech

Published online 09, November, 2011

Published in print edition November, 2011

This book summarizes current literature about research and clinical science in glaucoma and it is a synopsis and translation of the research conducted by individuals who are known in each of their respective areas. The book is divided into two broad sections: basic science and clinical science. The basic science section examines bench- and animal-modeling research in an attempt to understand the pathogenesis of glaucoma. The clinical science section addresses various diagnostic issues and the medical, laser and surgical techniques used in glaucoma management.

\title{
How to reference
}

In order to correctly reference this scholarly work, feel free to copy and paste the following:

Claudio De Seta, Nicola Calandrella, Valerio Berardi, Antonio Mazzarelli, Gianfranco Scarsella and Gianfranco Risuleo (2011). Role of the Matrix Metallo-Proteinases in the Cellular Re-Modeling in a Glaucoma Model System in Rat, Glaucoma - Current Clinical and Research Aspects, Dr. Pinakin Gunvant (Ed.), ISBN: 978-953307-263-0, InTech, Available from: http://www.intechopen.com/books/glaucoma-current-clinical-and-researchaspects/role-of-the-matrix-metallo-proteinases-in-the-cellular-re-modeling-in-a-glaucoma-model-system-in-rat

\section{INTECH}

open science | open minds

\section{InTech Europe}

University Campus STeP Ri

Slavka Krautzeka 83/A

51000 Rijeka, Croatia

Phone: +385 (51) 770447

Fax: +385 (51) 686166

www.intechopen.com

\section{InTech China}

Unit 405, Office Block, Hotel Equatorial Shanghai

No.65, Yan An Road (West), Shanghai, 200040, China

中国上海市延安西路65号上海国际贵都大饭店办公楼 405 单元

Phone: +86-21-62489820

Fax: $+86-21-62489821$ 
(C) 2011 The Author(s). Licensee IntechOpen. This is an open access article distributed under the terms of the Creative Commons Attribution 3.0 License, which permits unrestricted use, distribution, and reproduction in any medium, provided the original work is properly cited. 